\title{
Analysis and Countermeasures of Current Situation of Sex Education for Children Aged 3-6
}

\author{
Chaoyan Chen \\ Wenzhou University \\ E-mail: 1965325830@qq.com
}

\begin{abstract}
This article starts from the important significance of implementing sex education for preschool children, and analyzes the problems existing in the implementation of sex education in kindergartens in Ningbo, Zhejiang. From the teacher's point of view, it is proposed to use picture books as an entry point, combined with children's own interests, and make suggestions for teachers' solutions.
\end{abstract}

Keywords: Preschool Education ;Sex Education

\section{The importance of sex education for preschool children}

Although the kindergarten has set up books related to sex education for children to read by themselves, in the specific teaching activities of the kindergarten, teachers have not officially opened activities related to universal sex education knowledge for children6. Moreover, real-life cases of child sexual abuse do not stop it happening. For children, according to the theory of Freud's sexual development2, children in two and a half years old when he was gradually revealed its genital interest, although in the daily teaching, the teachers and parents do for this kind of phenomenon the guidance for young children, but most do not conform to the guidance of the child's needs, there still exists certain of adult guidance to its dark color and cover color. Therefore, it is particularly important for teachers to provide correct, scientific and objective sex education for preschool children aged 3-6 years1.

\section{Problems in sex education for preschool children in kindergartens}

\subsection{Lack of teaching materials for sex education for preschool children}

In children aged 3-6 years, unintentional attention dominates, and intentional attention gradually develops. In the day-long activities of kindergarten, teachers often take items that easily arouse children's interest and children like as the carrier of educational activities. However, sex education activities for children mainly rely on picture books. But at present, domestic about sex education in our country does not have many picture books types, most of the picture books such as "Little Granville Rush", "Little Penis Story", "Breast Story" 5 , each age level of part of the kindergarten children have seen many times in the home or garden books Angle, these picture books for children has been a lack of novelty. Secondly, the teaching videos selected by teachers or the videos played in children's leisure time are mainly about safety education, with little content related to sex education ${ }^{6}$.

\subsection{The quality of teachers needs to be improved.}

At present, in-service teachers in kindergartens in China only have a limited understanding of sex education ${ }^{2}$ to protect children themselves from encroachment, that is, sex education in physical aspects. The reason for this is that the professional quality of teachers is not strong, the teacher before the inauguration, both in its course in school or kinder-

Copyright (C) 2020 Chaoyan Chen

doi: 10.18282/le.v9i7.1463

This is an open-access article distributed under the terms of the Creative Commons Attribution Non-Commercial License

(http://creativecommons.org/licenses/by-nc/4.0/), which permits unrestricted non-commercial use, distribution, and reproduction in any medium, provided the original work is properly cited. 
garten training arranged by lack of education system, which makes every teacher for young children on the implementation of sex education methods, focusing on the content are not the same, and the teachers are often focus on what they think of as the key point of education, but in the actual teaching process teachers itself is hard for sex or sex organs can do an objective science is not a personal shy emotion.

\subsection{The low awareness of sex education in kindergartens leads to the lack of sex education courses in kindergartens.}

Compared with the west, China's sex education is nearly 20 years later. At present, the mainstream society can accept the implementation of sex education in the upper grades of primary schools, middle schools and high schools. But in fact, the children have already shown strong curiosity about sex when they enter the kindergarten, but the kindergarten has not given appropriate thematic activities. As a result, preschool teachers want to set up related sex education themed activities for children, but they have to leave this plan idle or intersperse it in children's daily activities ${ }^{3}$ due to the tight class hours in the semester.

In addition, the traditional thought ${ }^{9}$ of the society also limits the kindergarten to mention the sex education curriculum in the teaching practice, which limits the lack of this curriculum. However, the guidance for the learning and development of children aged 3-6 does not mention and clearly points out that teachers should grasp the important and difficult points of children's sex education, which directly aggravates the phenomenon of preschool children's lack of sex education.

\subsection{Teachers' lack of respect for children}

Some small classes (3 years) male children in ordinary life has demonstrated that the behavior of the stroke his penis, but when the preschool teachers to face this phenomenon, especially the young unmarried female teacher, they will be due to their inherent thinking, for young children to make unreasonable education countermeasures, such as deliberately exaggerated consequences: chicken chicken will be bad, and for children to make one-sided evaluation, such as: why are you so naughty, or are directly for young children to stop such conduct.

\section{Countermeasures for preschool teachers to effectively carry out sex education}

\subsection{Make full use of limited educational resources}

When conducting sex education, teachers should make full use of existing picture books. They should not only teach children by explaining picture books to them, but also make them master the teaching objectives put forward by teachers in the way of "learning by doing". For example, Teachers can pay attention to the cartoons that children like in their daily teaching activities, and cut out the fragments related to sex education in the cartoons. Combining with picture books, they can use vivid and interesting animation videos and teachers' vivid language to closely combine children's own interests with the safety skills that teachers want to pass to children. In addition, teachers can also subtly extend picture books. For example, before children take a nap, the clothes of boys who ask children questions about themselves should not be taken off during the nap. When children go to the toilet, if they feel strange about their way of going to the toilet, they need to explain them directly in a normal state of mind, and use this as a case for the next sex education and education activities, so as to infiltrate the safety knowledge contained in picture books into every aspect of life.

\subsection{Combining international trends and paying attention to fresh educational resources}

Effective use of Internet resources, such as university MOOC, bilibili, Google and other software websites.Focus on the domestic outside the advanced progressive sexual education teaching way and sex protection classes for children and channel, summarizes the present universal sex education draw bent points, ${ }^{3}$ analysis suitable for ages 3 to 6 years of age in preschool education countermeasures and methods of the suitable for all ages, implement step by step "walk" education method, the sex education throughout the kindergarten education stage step by step.

\subsection{Strengthen information exchange among peers and sum up teaching experience}

Teachers should adjust their dimensions of key and difficult points in sex education, communicate with peers about problems encountered in actual sex education teaching practice, reflect on problems neglected by themselves, try to communicate and summarize educational countermeasures, and apply them in educational practice again. 


\subsection{Break the shackles of original concepts and establish a scientific and objective attitude}

Teachers should be sensitive to children's interest points in getting along with children, do not look at problems through adults' colored glasses, and respond to children's curiosity about sex in a direct but simple and understandable way, without deliberately avoiding children's curiosity about sexual organs ${ }^{8}$. Second, make sure when to answer children's answer is correct and scientific, and accurate direct tell children how to protect themselves, let the children know what is as long as each other to do let oneself feel uncomfortable contact, all these behaviors can be attributed to sexual harassment, child can directly loudly of say “you can't do this, I am still young, do you want to go to jail?" And keep parents informed.

\subsection{To be a bridge between homes and to effectively integrate knowledge at home in the park}

Not only to do the kindergarten for the ordinary parents information transfer, more parents to do for the work of children's sex education enlightenment and guide ${ }^{10}$, when parents to park the appropriate introduction to the importance of education for parents, in the face of on sex education holds closed exclusive ideas of parents can be learned from normal children in the park first safety education, and gradually let parents sex education, through the analysis of the case reality as well as the other children in class master degree of knowledge about sex protection, let parents understand the importance of sex education, thus to achieve the effect of two sides teach home grounds, at the same time improve the dual safety awareness of parents and children. For parents with a positive and objective attitude towards sex education, they should actively communicate and cooperate with their families. They should start from the trivial things in daily life, be attentive people in daily life, and explore the sex education suitable for their children together.

\section{References}

1. Pan Yalu. Practical Exploration of preschool Children's Sex Education using picture Books [J]. Journal of Ningbo Institute of Education, 2012,20(02):112-116.

2. Chen Mingying. Research Progress and Countermeasures of Sex Education for Children at home and abroad [J]. Psychological Health Education for Primary and Secondary Schools,2016(12):8-10+14.

3. Xie Yufei, Ren Xuemin, Li Yunping.Development and implementation of kindergarten sex education curriculum [J]. Educational observation,2019,8(12):17-18.

4. feng Ming. Discussion on the current situation and methods of preschool children's sex education [J]. Journal of chongqing institute of education,2012,25(02):115-117.

5. Xie Ni. Research on the implementation status, reasons and countermeasures of preschool Children's sex education [D]. Northwest Normal University,2003.

6. Ren Xuemin, Xie Yufei, Liu Yimin, Xue Wei.Application and Analysis of Picture Books in Early Childhood Sex Education [J]. Wind of Science and Technology,2020(05):223.

7. Hu Xinxin, Liu Xiangguo.Research on the Development Status and Countermeasures of Sex Education for Children in China [J]. Education Modernization, 2015,5(02):203-204+207.

8. sun dianwei. Research on current status and countermeasures of preschool children's sex education [J]. Journal of weifang vocational college of engineering,2016,29(03):49-51.

9. pang lijuan. Accelerating the legislative process of preschool education law [J]. Education research,2011,32(08):35-38.

10. Guo Jialing. Research on integrated social work Method's involvement in adolescent Sex education of migrant Children [D].Yunnan University,2014. 